\title{
O CARÁTER NADIFICADOR DA CONSCIÊNCIA IMAGINANTE
}

\author{
[THE NIHILATED CHARACTER FROM THE IMAGING CONSCIOUSNESS]
}

\begin{abstract}
Resumo: Este ensaio visa explicitar o conceito de analogon em sua relação com o real. A consciência imaginante tem um modo próprio de intencionar os objetos, operando um ato nadificador que ultrapassa o real. Através do conceito de analogon, essa consciência realiza um movimento no qual, deixa a percepção do real em segundo plano e visa o irreal. A arte, por sua vez, permite questionarmos a tensão entre esses pontos. Segundo Sartre, o objeto estético está no irreal, ele opera a passagem da consciência perceptiva à consciência imaginante. Embora represente uma fuga da realidade, $\mathrm{o}$ ato nadificador da consciência imaginante não decorre da alienação do sujeito. A fuga é aparente, dado que, a nadificação da consciência deriva da atividade humana de olhar o mundo e, através da imaginação, visar uma imagem que provoca um reposicionamento diante dele. A obra da arte é a manifestação da liberdade artística de negar o real e, ao mesmo tempo, modificá-lo implicitamente.
\end{abstract}

Palavras-Chave: Imaginário; Jean-Paul Sartre; Analogon; Objeto estético; Alienação
Abstract: This paper aims to clarify the concept of analogon in relation to the real. The Imaging consciousness has its own way of intending objects, it operates an act that nihilates and surpasses the real. Through the concept of analogon, this consciousness makes a movement in which it leaves the perception of the real in the background and aims at the unreal. Art, in turn, allows us to question the tension between these points. According to Sartre, the aesthetic object is in the unreal, it operates the passage from perceptual consciousness to Imaging consciousness. Although it represents an escape from reality, the nihilated act of the imaging consciousness does not result from the alienation of the subject. The trail is apparent, since the nihilation consciousness derives from human activity and look at the world through imagination, targeting an image that causes a repositioning before him. The work of art is the manifestation of artistic freedom to deny the real and, at the same time, to modify it implicitly.

KEYWORDS: Imaginary; Jean-Paul Sartre; Analogon; Aesthetic object; Alienation

\section{INTRODUÇÃ̃o}

D e acordo com Sartre, existe uma escolha deliberada contida no gesto criador do artista, anterior às escolhas dos espectadores, um desejo de estar para além das limitações do real. A realidade do mundo depende do gesto perceptivo, acompanhado pela consciência, que faz o homem ser "desvendante", isto é, o meio pelo qual as coisas se manifestam:

* Mestrado em Filosofia pela Universidade Estadual de Maringá (2019). m@ilto: lucas_rodrigues_lopess@yahoo.com.br 
Somos nós que colocamos essa árvore em relação com aquele pedaço de céu; graças a nós essa estrela, morta há milênios, essa lua nova e esse rio escuro se desvendam na unidade de uma paisagem; é a velocidade do nosso automóvel, do nosso avião que organiza as grandes massas terrestres; a cada um dos nossos atos, o mundo nos revela uma face nova. (SARTRE, 2004, p. 34).

O teor da citação é importante, pois afirma que o homem é responsável pelas coisas, estabelecendo as relações entre elas, ordenações hierárquicas, tabelas de valores. Apesar de ser o responsável pela ordem do mundo, ele sabe também que não é o produtor das coisas naturais, sendo inessencial em relação a elas. Diante disso, um dos principais motivos pela escolha da criação artística é a necessidade de se sentir essencial em relação ao mundo. "Este aspecto dos campos ou do mar, este ar de um rosto, por mim desvendados, se os fixos numa tela ou num texto, estreitando as relações, introduzindo ordem onde não havia nenhuma, impondo a unidade de espírito à diversidade da coisa, tenho consciência de produzi-los" (Idem, Ibidem). As coisas do mundo existem enquanto seres-em-si. "Desconhecem, pois, a alteridade; não se coloca jamais como outro a não ser si mesmo; não pode manter relação alguma com o outro. É indefinidamente si mesmo e esgota-se em sê-lo" (SARTRE, 1997, p. 39). O ser Em-si é pleno de si, sem relações com os outros seres. Consequentemente, é preciso de um outro ser para estabelecer essas relações, isto é, um ser que seja o oposto do Em-si. E isso é feito por meio do Ser-para-si, que é pura negatividade (SARTRE, 1997, p, 38). É um ser que se lança aos outros seres numa busca por seu ser. O homem estabelece as relações entre as coisas, no entanto, a existência delas não cabe a ele. Ao ver uma pedra, por exemplo, ela só ganha significado devido ao sujeito que a observa, mas se ele cessar de vê-la, ela apenas perde o significado conferido, não sua existência. Assim, "ao perceber uma paisagem, o homem se descobre em sua importância e insignificância: essencial para o desvendamento do em-si, mas inessencial para a existência dele" (SOUZA, 2008, p. 79). Por essa razão, podemos perceber o desejo do artista, ele almeja ser essencial em relação ao mundo, deseja ser uma síntese do "Em-siPara-si". Ao criar algo no mundo, torna-se um ser que seria seu próprio fundamento (SARTRE, 1997). "O artista é aquele que tenta alcançar o Em-si-Para-si através da criação: sua percepção the revela a inessencialidade de que tanto quer escapar e a criação artística se apresenta com o meio de ser essencial à existência das coisas" (SOUZA, 2008, p. 80). O homem é marcado pelo desejo de preencher sua falta de ser, mas jamais será bem sucedido em sua busca de ser causa de si. Contudo, ele tenta realizar esse desejo por meio da criação artística:

O que faz de um escritor, escritor, é ver a criação artística como meio de se sentir essencial ao mundo: se todos os homens querem ser essenciais, os escritores são aqueles que escolhem a criação como possibilidade de chegar à essencialidade. [...] Por meio da criação artística o artista tenta ser essencial à existência do objeto. (SOUZA, 2008, p.80).

O plano da percepção, como âmbito do desvelamento e da inessencialidade, faz com que o artista busque um meio de se afirmar. Para sair desse plano "limitado" em relação à essencialidade das coisas, é preciso imaginar. A teoria de Sartre sobre a imaginação nos oferece o irreal como oposto ao real, estabelecendo uma divisão nítida entre esses dois polos. Por conseguinte, cabe questionarmos essa "saída" do artista em relação ao real e olharmos mais de perto as estruturas do imaginário. Se há essa oposição, como é possível o artista se realizar no imaginário sem alienar-se? Se o imaginário é o lugar do objeto estético, poderá esse objeto reaproximar-se do real? Por mais que a teoria de Sartre encaminhe à alienação do sujeito, a alienação é aparente. 
Como veremos a seguir, há um conjunto de argumentos que demonstram o contrário, onde o recurso ao imaginário é inserção no mundo e resultado do engajamento.

\section{CONSCIÊNCIA IMAGINANTE E IMAGEM.}

Como Sartre considera a consciência da imagem? De acordo com esse autor, a consciência é dotada de uma translucidez que é própria do modo de Ser-Para-si, caracterizado pela falta de ser.

[...] a consciência está purificada, está clara como uma ventania, não há mais nada nela a não ser um movimento para fugir de si, um deslizar para fora de si; [...], pois a consciência não tem "interior"; ela não é nada senão o exterior de si mesma, e é essa fuga absoluta, essa recusa de ser substância que a constitui como uma consciência. (SARTRE, 2005, p. 56).

O Para-si define-se como pura presença, como um "estar diante de...”. Em seu movimento intencional, define-se como um "atirar-se a...". O Para-si se identifica com aquilo que ele não é e se projeta a um ser em busca de um possível. Se consciência é sempre consciência de alguma coisa, então, para compreendermos essa relação entre a produção do artista e o imaginário, é necessária uma investigação sobre o modo como a consciência se posiciona perante tais objetos. Ora, o objeto artístico não é um objeto qualquer. Por esta razão, é fundamental, para Sartre, o conceito de analogon. Este conceito remete diretamente à noção de consciência imaginante e ao caráter negativo da imagem. O que é a consciência imaginante?

Longe de tratar a consciência como passividade, a imagem, para Sartre, não pode ser tomada como algo que ocupa um lugar na consciência, nem mesmo como ideia fraca ou percepção enfraquecida. Além disso, um erro muito comum é pensar que a imagem estava na consciência e que o objeto da imagem estava na imagem. Este erro é denominado de "Ilusão da Imanência". Segundo Sartre, sua expressão encontra-se mais clara em Hume: "As percepções que penetram com mais força e violência podem ser chamadas de impressões... Por ideias, entendo as imagens fracas oriundas das primeiras no pensamento e no raciocínio" (SARTRE, 1996, p. 18). O erro está em fazer da consciência apenas um lugar povoado de simulacros, no qual todas as qualidades e quantidades que pertencem ao objeto devem também estar presentes na ideia deste objeto. Sartre rejeita a Ilusão da Imanência, pois, percebendo ou imaginando um objeto, ele permanece sempre fora da consciência como objeto real exterior a ela. Assim, o objeto não existe através da imagem, sua imagem é apenas uma ideia que se forma a partir do que aparece no mundo exterior. É falso pensar a imagem como sendo o seu próprio objeto, visto que a imagem é uma consciência de forma semelhante à percepção. Por conseguinte, não é correto afirmar que o objeto da percepção está na percepção.

Quando percebo uma cadeira, seria absurdo dizer que a cadeira está em minha percepção o. Minha percepção é, segundo a terminologia que adotamos, uma certa consciência, e a cadeira é um objeto dessa consciência. No momento, fecho os olhos e produzo a imagem de cadeira que acabo de perceber. A cadeira, dandose imediatamente como imagem, não poderia mais do que antes entrar na consciência. Uma imagem de cadeira não é, não pode ser, uma cadeira. $\mathrm{Na}$ realidade, quer eu perceba, quer eu imagine a cadeira de palha na qual estou sentado, ela permanece sempre fora de minha consciência. (Idem, p. 20).

Percebendo ou imaginando, os objetos da percepção e de minha imagem são 
idênticos, e eles permanecem sempre fora da consciência, inalterados. A diferença está nos modos como a consciência se relaciona com estes objetos, isto é, a forma como ela os intenciona ${ }^{1}$. Em ambos os casos a cadeira, por exemplo, é visada em sua individualidade concreta. Deste modo, quando percebo uma cadeira, ela é visada como um ser-no-mundo e não como uma representação ou um conteúdo mental, pois é próprio da consciência lançar-se em direção a um ser que está fora dela. Assim, a cadeira não está na consciência no sentido de um simulacro sem nenhuma relação com a cadeira existente. Portanto, a imagem é uma relação da consciência com o objeto, é o modo como os objetos aparecerem à consciência ou um modo como a consciência apreende um objeto ${ }^{2}$. Cada forma de consciência tem por intenção certos modos de disposição em relação a objetos. Tanto o objeto percebido como o objeto imaginado compartilham desta característica, entretanto, eles diferem em seu modo de existir.

Ao posicionar um objeto na percepção, sua apreensão se realiza de forma mais lenta, sendo preciso que seja feita de diversas formas, pois este objeto aparece como uma série de projeções nas quais, cada vez que se dirige ao objeto, um de seus lados acaba sendo invisível. Contudo, ainda que o objeto entre por inteiro em minha percepção, o que é me dado é somente um lado de cada vez. Só se conhece um cubo, por exemplo, a partir do momento em que são aprendidas suas seis faces. É próprio da percepção que o objeto apareça a partir de uma série de perfis, uma vez que o objeto em si é a síntese de todas suas aparições, é preciso dar a volta aos objetos, ver sua infinidade de faces, "Esperar que o açúcar derreta" (Idem, p. 21). Diferente de quando intencionamos algum objeto pela concepção, que seria pensa-lo por meio de conceitos. Por exemplo, pensar o cubo através de seu conceito é pensar nos seus seis lados e oito ângulos ao mesmo tempo. Pensa-se em algo e ele já se apresenta como uma totalidade. Num ato de consciência posso restabelecer aparências, porém, sem nenhuma aprendizagem. Uma diferença entre pensamento e percepção é que não podemos perceber um pensamento e nem pensar uma percepção, são fenômenos distintos, pois, no primeiro caso, o saber consciente de si mesmo é o centro do objeto e, no segundo, a unidade sintética de aparências guia o aprendizado. Na percepção o saber é construído lentamente, enquanto que na concepção ele é imediato. "A imagem é um ato sintético que une a elementos mais precisamente representativos um saber concreto, não imaginado" (Idem, Ibidem). Segue-se que a imagem não produz um ganho de conhecimento, mas ela é organizada como os objetos que se aprende, ela se apresenta como aquilo que ela é, desde seu aparecimento até seu fim. Logo, a imagem é uma consciência que se localiza entre a percepção e a concepção. Se na percepção ocorre um conhecimento a cada revelação de suas projeções, na imagem encontra-se apenas aquilo que se colocou. Segundo Sartre, ao olharmos uma folha de papel pousada sobre a mesa, quanto mais se olha, mais ela nos fornece seus detalhes, seja a margem superior curvada da folha, ou o traço mais escuro em determinada linha, por exemplo. Podemos reter em nossa imaginação uma imagem pelo tempo que quisermos e só encontraremos o que tivermos colocado ali. Na percepção, por outro lado, uma coisa não pode aparecer sem que mantenha uma infinidade de relações com o seu entorno. Na imagem, ao contrário, há uma pobreza essencial, pois os seus elementos não mantêm nenhuma relação com a exterioridade. Cito Sartre: "Duas cores, por exemplo, que manteriam na realidade certa relação de discordância, podem coexistir na imagem sem que tenham entre si nenhuma espécie de relação" (Idem, p. 22). Os objetos só existem enquanto pensamos:

O objeto como imagem é contemporâneo da consciência que tomo dele, e ele é exatamente determinado por essa consciência: não compreende nele nada além 
daquilo que tenho consciência; mas, inversamente, tudo que constitui minha consciência encontra seu correlativo no objeto. (Idem, p. 24).

Todavia, por mais que o objeto da imagem se apresente como algo a ser apreendido através de uma multiplicidade de atos sintéticos, semelhante ao objeto da observação, a imagem nada ensina, pois ela não pode dar a impressão do novo ao lançar luz sobre outra face do mesmo objeto, movimento característico da percepção. Eis que surge então o fenômeno característico da imagem, a Quase-observação, uma atitude que, diferentemente da percepção, nada ensina. "Nem observação (percepção), nem saber consciente de si (concepção), a imaginação se encontra num terreno ambíguo, entre ambos os modos, entre a percepção e a concepção: ela é uma observação que nada aprende" (SOUZA, 2008, p. 87). Na imagem, certa consciência se dá a certo objeto que, por sua vez, é correspondente a um ato sintético, o qual compreende um saber e uma intenção. A intenção está no centro da consciência, sendo ela que visa o objeto e constitui o que ele é. Constituir a consciência como imagem é constituí-la como uma consciência imaginante. Conhecer essas características da imagem e o conceito de Quase-observação é fundamental para a relação entre a arte e o real, o mundo imaginário e o mundo real ${ }^{3}$.

Diferentemente da consciência perceptiva, que coloca seu objeto como existente, a consciência imaginante coloca seu objeto como uma falta, uma ausência. Ela se relaciona com ele negando sua presença, colocando-o em um ato de crença posicional que pode ser inexistente, ausente, existente em outra parte ou neutro (SARTRE, 1996). Em outras palavras, colocar o objeto como inexistente ou ausente é operar um ato de negação, por exemplo, quando imagino algum ser mitológico, no caso, um centauro, nego a sua existência real. Quando imagino uma pessoa, realizo neste ato uma negação de sua presença, afinal, se ela estivesse presente não seria preciso imaginá-la. Por sua vez, quando a consciência posiciona o objeto como existente em outro lugar, temos um ato positivo que pressupõe a negação do objeto, por exemplo, posso imaginar Pierre em seu trabalho. Ao fazê-lo, afirmo a presença de Pierre no trabalho ao mesmo tempo nego a sua presença ao meu lado. Por fim, o quarto ato posicional é uma neutralização da tese. Posso olhar uma fotografia com uma pessoa retratada nela e formar uma imagem que não será colocada nem como inexistente, nem ausente, nem mesmo existindo em outro lugar, sendo apenas intencionada. Não associo essa imagem a alguém. Neste caso, a imagem será apenas visada em sua irrealidade. Estes atos posicionais não se acrescentam à imagem uma vez já constituída, pois são constitutivos dela. Como aponta Sartre: "A imagem deve conter em sua própria estrutura uma tese nadificadora. Constitui-se como imagem designando seu objeto como existente em outro lugar ou não existente" (SARTRE, 1997, p. 69). O autor nos possibilita entender que a estrutura fundamental da imagem é uma negatividade, uma ausência, ou até mesmo inexistência de algo ou alguém. A imagem é dada por uma existência irreal, possibilidade tal que é sustentada pelo ser do Para-si, que possui natureza nadificadora. Em O Ser e o Nada (1943), Sartre cita o seguinte exemplo: Pedro atrasa-se para o encontro que havia marcado com o amigo no bar. Quando o amigo chega ao ponto marcado, busca a presença de Pedro, as cadeiras, as mesas e as pessoas que estão lá, todos estes elementos formam uma totalidade num plano de fundo não visado pela consciência. Isto acontece porque a consciência tem como objeto intencionado a presença de Pedro. "Quando entro nesse bar em busca de Pedro, todos os objetos assumem uma organização sintética de fundo sobre a qual Pedro é dado como 'devendo aparecer'. E esta organização do bar em fundo é uma primeira nadificação (SARTRE, 1997, p. 50). Ora, o processo de nadificação também ocorre com o objeto estético criado pelo artista.

$\mathrm{Na}$ imagem, seu objeto intencional carrega consigo uma característica particular, 
Pierre não está aqui, mas é posto como tal. Dizer "Eu tenho uma imagem de Pierre", equivale a dizer "eu não vejo Pierre", mas também "eu vejo nada". "O objeto intencional da consciência imaginante tem isto de particular: que ele não está aí é posto como tal, ou que ele não existe e que é colocado como inexistente, ou, ainda, que não é colocado de modo algum" (SARTRE, 1996, p. 27). Tal é a característica posicional da imagem, a saber, seu caráter negativo. Produzir a consciência imaginante de algo é fazer uma síntese intencional do objeto reunindo em si momentos passados, afirmando sua identidade através de suas aparições. A imagem é sustentada pela consciência e o ser que sustenta o fenômeno da imagem é a negatividade, diferentemente da consciência perceptiva que aparece como passividade, uma vez que o objeto da percepção possui um ser que não pode ser negado pela consciência imaginante.

Conhecendo algumas características da imagem e da consciência imaginante, o segundo passo é verificar como a imagem se realiza e qual a sua matéria. Aqui entra o analogon, conceito chave que possibilita a manifestação das imagens e consequentemente da figura estética. Ora, é possível realizarmos uma comparação de três tipos de imagens: a imagem mental, o retrato e a caricatura (exemplos que o próprio Sartre utiliza). Quando realizamos um esforço para produzirmos uma consciência imaginante de algo, como tentar reproduzir mentalmente o rosto de alguém, o objetivo é alcançado, mas de um modo imperfeito, pois faltam detalhes, tornando vaga a imagem. Entretanto, ao observarmos uma fotografia dessa mesma pessoa, é possível ver todos os detalhes de seu rosto. Contudo, se olharmos para uma caricatura, com todos seus "toques" extravagantes, nos depararmos com o que na fotografia está ausente, a saber, a sugestão de características de vida colocada sobre a imagem, uma espécie de emoção. Em todos estes casos citados encontrarmos uma "intenção" que visa um mesmo objeto, sendo que este objeto não é nem a representação, nem a foto, nem a caricatura, mas um objeto estético. Nas palavras de Sartre:

Nos três casos, viso o objeto da mesma maneira: é no terreno da percepção que eu quero fazer aparecer o rosto de Pierre, que quero 'torná-lo presente'. Mas, como não posso fazer surgir sua percepção diretamente, sirvo-me de uma certa matéria que serve como analogon, como um equivalente da percepção. (Idem, p. 34).

O analogon é o suporte material equivalente da percepção, uma vez que os objetos das imagens não podem surgir da percepção diretamente ${ }^{44}$. Na fotografia e na caricatura, as suas matérias podem ser percebidas por si mesmas como sendo "uma coisa". Pela fotografia é possível, através de suas cores, determinarmos o tempo de sua exposição e o produto que a fixou. Na caricatura, podemos tirar conclusões através de alguns estudos sobre suas linhas e cores sem pensar que essas linhas têm como função representar algo, sendo necessária apenas uma intenção que as interprete como imagem. No entanto, se percebemos a fotografia como a "foto de um homem na escada", o fenômeno da intenção passa a interpretá-la de outra maneira. O mesmo ocorre quando nos deparamos com uma foto e reconhecemos a pessoa que está nela. Ora, na imagem mental não temos o suporte de alguma matéria. Ao querermos representar alguma coisa, é necessário algo para preencher esta intenção, algo que possa servir de ponte e conexão para o objeto desejado, tal como um analogon. Através do analogon, a consciência imaginante ultrapassa o que é visto, ultrapassando o real, colocando-o em um plano de não-ser por meio da nadificação e abstraindo a sua imagem. $\mathrm{O}$ analogon atua como um suporte que vai para além da percepção alcançando o que é irreal. Assim, do mesmo modo que para a consciência formar imagens é preciso colocar uma tese de irrealidade, isso se aplica ao objeto estético, em razão de que ele é apreendido quando se tem um distanciamento do real. "Se a consciência imaginante é derivada da faculdade de negar 
que seria integral, a definição de obra de arte como sendo um irreal é, segundo esta perspectiva, necessária" (GUIGOT, 2013, p. 82). Posicionar-se diante de uma obra enquanto objeto estético exige da consciência um comportamento a ponto de colocar aquilo que não é intencionado como um pano de fundo, nadificando a realidade, alcançando a imagem enquanto um irreal.

Diante de um quadro, por exemplo, podemos ter vários modos de olhá-lo. $\mathrm{O}$ primeiro, que viria da consciência perceptiva, perceberia as perspectivas, o jogo de sombra e luz; e o segundo, que seria a consciência imaginante, não se concentraria nessas características, mas colocaria tudo isso como pano de fundo do qual sairia o sentido do quadro, o sentido mesmo do que é visto. (SOUZA, 2010, p. 89).

Em uma obra de arte, o objeto estético não é o suporte, mas aquilo que é representado. Ele é irreal. Eu não julgo o quadro pela moldura. O objeto estético é produzido através de uma atuação imaginante, no qual realiza uma passagem da realidade para a irrealidade. Seja qual for, ele não se oferece apenas pela percepção, mas com a atuação imaginação. "O real é convertido em analogon do objeto irreal, por uma mudança de atitude da consciência, que se torna então imaginante, irrealizante, e aprende o objeto estético como imaginário.” (MOUTINHO, 2009, p. 306).

Portanto, pelo analogon, a consciência imaginante procura transcender-se colocando seu conteúdo como existente. Desse modo, quando apreendemos uma imagem ou uma obra de arte, realizamos um ato de nadificação através da consciência imaginante que coloca o real como um pano de fundo para alçarmos o irreal onde estão as imagens e as produções artísticas.

\section{AlienaÇão OU NADIFICAÇão}

A obra de arte permite questionar a tensão entre o real e o irreal. Em A Náusea, romance de 1938, Roquentin percebe a contingência da realidade e, ao mesmo tempo, a arte como salvadora, pois nos momentos que ouve uma música, a náusea não o atormenta. "O que acaba de ocorrer é que a Náusea desapareceu. Quando a voz se elevou no silêncio, senti meu corpo enrijecer e a Náusea se dissipou" (SARTRE, 2016, p. 38). O que acontece é que "sua consciência se desvia da existência, niiliza - ou nadifica - as circunstancias da situação concreta, e se absorve nesse objeto inexistente, bem-ordenado, com tempo próprio, com começo e fim definidos." (LEOPOLDO E SILVA, 2004, p. 102). Roquentin vai sentindo um mal-estar que cresce até chegar a grandes proporções, gerando momentos em que as coisas adquirem um aspecto insuportável. Ele sente o peso da existência e da contingencia caindo sobre seus ombros.

A vida não é um romance de aventuras - descobrirá Roquentin - porque ela não depende de um narrador que articule os eventos e faça que a história vivida se produza a partir dessa articulação, o que significaria que se poderia contar com o fio da narração como suporte dos acontecimentos e como sustentáculo temporal. (Idem, p. 82).

Ora, o imaginário aparece para Roquentin como algo que the permite recuar diante do mundo e negá-lo. "O mundo contingente é inseparável da inquietude e da incerteza. Por isso, o sujeito abre para si mesmo a possibilidade de criar 'seu próprio objeto', ideá-lo liberto da contingência perceptiva" (Idem, p. 104). Por meio do imaginário, a arte alcança a propriedade de ser algo que não é contingente, mas, 
necessário.

É assim que Roquentin gostaria que fosse a sua vida: duração melódica, qualitativamente necessária, previsível e exata. Em cada momento dessa duração, pode-se esperar o que vai acontecer: a música não nos decepciona. Todos os instantes são necessariamente preenchidos; tempo e acontecimento regidos pela mesma necessidade. (Idem, p. 91).

Se olharmos mais atentamente para a forma que Sartre encadeia seus argumentos sobre a consciência imaginante e o analogon, é possível pensar que o imaginário produz uma espécie de alienação, uma fuga da realidade. Sobre a imaginação, Sartre afirma que: "O ato de imaginação, como acabamos de ver, é um ato mágico. É um encantamento destinado a fazer aparecer o objeto no qual pensamos, a coisa que desejamos, de modo que dela possamos tomar posse" (SARTRE, 1996, p. 165). Deste modo, esse objeto não está presente, não posso tocá-lo. "O imaginário, como já vimos, envolve o nada, se define por ser a negação explícita ou implícita da existência natural do objeto" (SOUZA, 2008, p.90). Isso é assim porque o real é o plano da contingencia, da liberdade, da situação ${ }^{5}$. O imaginário, enquanto negação, é o plano da necessidade, da abstração, da fatalidade, no qual o artista seria aquele que sai da contingência e constrói uma irrealidade necessária, onde tem o controle de tudo. Esse seria o papel que a negação exerceria no imaginário, sendo um lugar de alienação do homem, um isolamento e defesa das contingências esmagadoras da existência humana para ficar num plano de necessidade, ainda que apenas no plano irreal, que só é possível através do imaginário. Segundo Thana Mara de Souza (2008, p. 91), alguns comentadores assumem essa posição diante da imaginação e compreendem o imaginário como o lugar da alienação e da má-féc. Por meio da má-fé, o sujeito nega a si mesmo. Um dos exemplos utilizados por Sartre é o caso da mulher que vai ao primeiro encontro. Mesmo sabendo das intenções que o homem tem a seu respeito, mas por não querer perceber isso, ela apenas se atenta às atitudes de respeito do companheiro (SARTRE, 1997). Ela nega a realidade como uma forma de evitar e fugir das responsabilidades de seus atos e, do mesmo modo, o artista nega o mundo real buscando um refúgio no imaginário. No entanto, não devemos tomar a nadificação realizada pelo imaginário como uma forma de alienação e isolamento do homem ao mundo. O imaginário gera uma profunda inserção do homem no mundo como forma engajamento, pois a transcendência do imaginário, a sua possibilidade de negação, só é possível graças à inerência no mundo. "Chamaremos "situações" os diferentes modos imediatos de apreensão do real como mundo. Podemos dizer assim que a condição essencial para que uma consciência imagine é que ela esteja "em situação no mundo", ou mais brevemente, que ela "estejano-mundo" (SARTRE, 1996, p. 241). É o ser-no-mundo, apreendido como realidade concreta e individual da consciência, que serve de motivação para a constituição do objeto irreal cuja natureza é circunscrita por essa motivação. A situação da consciência não deve aparecer como uma pura e abstrata condição de possibilidade para todo imaginário, mas como motivação concreta e precisa da aparição de tal imaginário particular. "Assim, ainda que, pela produção do irreal, a consciência possa parecer momentaneamente libertada do seu "estar-no-mundo", é ao contrário, esse "estar-nomundo" que constitui a condição necessária da imaginação" (Idem, p. 242). Por conseguinte, a arte, enquanto produto da imaginação, coloca todo o plano perceptivo num pano de fundo, mas isso não quer dizer que se aliene. "A percepção - esfera da moral - encontra-se aqui como pura positividade, enquanto a imaginação - esfera da arte - é pura negativididade, é um movimento que nega o que é percebido para, a partir da negação, criar um outro mundo, um 'mundo irreal” (SOUZA, 2010, p. 89). Há uma 
separação entre esses dois domínios. Em $O$ imaginário, Sartre afirma que é um erro confundir moral e estética, pelo fato de que, enquanto a beleza está no plano irreal, os valores morais estão no mundo concreto, "[...] a beleza extrema de uma mulher mata o desejo de tê-la" (SARTRE, 1996, p. 252). Não podemos nos colocar no plano estético, no qual admiramos sua beleza e, ao mesmo tempo, no plano realizante, "pois o desejo é um mergulho no coração da existência no que ela tem de mais contingente e absurdo" (Idem, Ibidem). Entretanto, isso não quer dizer que o plano estético não possa incorporar o plano ético ou moral. "O fato de a arte ser obra do imaginário e a moral ser obra da percepção não implica pensar que uma não se relaciona com a outra. Mesmo que uma consciência seja irredutível a outra, uma pode motivar o aparecimento da outra e se voltar para ela" (SOUZA, 2010, p. 90). Quando o imaginário nega o real, essa negação gera uma intervenção sobre o mesmo. "Pois uma imagem não é o mundo negado, pura e simplesmente, ela é sempre o mundo negado de um certo ponto de vista, exatamente aquele que permite colocar a ausência ou a inexistência de um determinado objeto que será presentificado 'enquanto imagem"' (SARTRE, 1996, p. 240). A negação não é feita de modo abstrato. Por exemplo, para que um centauro apareça como irreal, é necessário que eu tenha consciência de que os centauros não existem. "Para a consciência, há muitas outras maneiras de ultrapassar o real para fazer dele um mundo: essa ultrapassagem pode ser feita a princípio pela afetividade ou pela ação" (Idem, p. 241). O sujeito parte de sua situação-no-mundo para construir o irreal. A criação imaginária não é arbitrária. "Há sempre um fundo de mundo e um vínculo com ele que jamais é ultrapassado totalmente. Portanto, enquanto a liberdade pertence à essência da consciência, o imaginário é uma possibilidade inscrita no real" (MULATRIS, 1999, p. 106). Conclui-se disso que o imaginário sempre retorna ao real. O plano estético sempre retorna ao plano moral. Um completa o outro e se sustentam.

$\mathrm{O}$ ato imaginário, ao negar o real ultrapassa-o, mas conserva-o como analogon, permitindo assim um retorno constante. $\mathrm{O}$ imaginário não é um abandono da realidade. Ao olharmos uma fotografia, a intencionalidade da consciência se dirige para o imaginário, porém, a fotografia, enquanto analogon material, permanece ali, servindo de apoio, sustentação e enriquecimento da construção irreal. "Não olhamos a foto apenas uma vez. Voltamos a ela várias vezes para recordar mais elementos, seja o dia, ou determinada expressão da pessoa que nem nos lembrávamos mais..." (SOUZA, 2010 , p. 90). Sempre que olhamos a foto, vamos acrescentando mais detalhes, o analogon da fotografia permite esse alcance do imaginário, mas também o retorno ao real. Deste modo, por mais que a imaginação realize uma negação da realidade e permita ao artista produzir o imaginário, a arte também faz com que ele desenvolva um olhar mais atento ao mundo que nega no interior do movimento dialético entre real e irreal, percepção e imaginação. "Naturalmente, a aparição da imagem exige que as percepções particulares se diluam no conjunto sincrético mundo e que esse conjunto recue. Mas é precisamente o recuo do conjunto que o constitui como fundo, esse fundo sobre o qual a forma irreal deve destacar-se" (SARTRE, 1996, p. 242). Se o imaginário, num primeiro momento, precisa da imaginação para negar e superar o que é visto, a recíproca também é verdadeira, a percepção precisa do imaginário.

Toda situação concreta e real da consciência no mundo está impregnada de imaginário na medida em que se apresenta sempre como uma ultrapassagem do real. Disso não se pode inferir que toda percepção do real deva inverter-se em imaginário, mas sim que a consciência está sempre "em situação" porque é sempre livre, para ela há sempre e a cada instante uma possibilidade concreta de produzir o irreal. (Idem, p. 243). 
Somente por meio do imaginário é possível abstrair aquilo que não é visto pela percepção e encontrar algo implícito ao real. "Entre a imagem e o real se estabelece uma dupla relação, um circuito que aumenta o próprio sentido do real e permite uma inserção recíproca entre o mundo e eu. Pois à medida que ultrapasso o real, assumo-o como este mundo em relação ao que este imaginário é uma falta" (BREEUR, 2005, p. 146). A relação entre a consciência perceptiva e imaginante ocorre de modo em que uma precisa da outra para acontecer. O plano estético, portanto, desdobra-se do plano ético, assim como o imaginário ancora-se no real.

Todo imaginário aparece "sobre o fundo do mundo", mas, reciprocamente, toda apreensão do real como mundo implica uma ultrapassagem velada em direção ao imaginário. Toda consciência imaginante mantém o mundo como fundo nadificado do imaginário, e, reciprocamente, toda consciência do mundo chama e motiva uma consciência imaginante apreendida como resultante do sentido particular da situação. (SARTRE, 1996, p. 245).

Em outras palavras, "a consciência realizante envolve sempre uma ultrapassagem em direção a uma consciência imaginante particular que é como avesso da situação e em relação à qual a situação se define" (Idem, p. 244). Por exemplo, se visamos uma pessoa ausente, a imagem dela é o que faz a totalidade se organizar e ser ultrapassada em direção ao irreal, já que a situação se definiu a partir de sua ausência. "A imaginação não é mais estritamente o contrário da percepção. Ela é aqui o que permite a percepção constituir o real no mundo" (GIOVANNANGELI, 2005, p. 51).

\section{CONCluSÃo}

Diante do que foi exposto, podemos afirmar que por mais que a arte e a moral sejam valores criados arbitrariamente pelo homem (SARTRE, 1987), percebe-se uma relação necessária entre ambos. $\mathrm{O}$ real é marcado por sua contingência e insegurança. $\mathrm{O}$ mundo está aí, ele acontece independente da vontade do sujeito. O resultado disso é o indivíduo buscar refúgio no imaginário, na arte, que o acolhe, mas que também lhe dá condições de olhar o mundo de outro modo. A arte se diferencia do mundo real, mas não como alienação ou ato de má-fé. É uma forma de recuo que, apesar do distanciamento e da negação, sempre retorna ao mundo e à ação. A consciência imaginante somente pode transcender-se para o irreal devido a sua relação de imanência ao mundo. $\mathrm{O}$ artista, mesmo quando nega o mundo, não se desliga dele, não o abandona, mas modifica-o, através do engajamento, o que lhe é possível.

\section{REFERÊNCIAS}

BAILLY, Anatole. Le Grand Bailly Dictionnaire Grec Français. Editeur Hachette, 2000.

BREEUR, Roland. Autour de Sartre, La conscience mise à nu. Grenoble: Millon. 2005.

CABESTAN, Philippe. Dictionnaire Sartre. Paris: Elipses, 2009.

GIOVANNANGELI, Daniel. Imaginaire, monde, liberte. In. BARBARAS, R. Sartre: Désir et liberte. Paris: Presses universitaires de France, 2005.

GUIGOT, André. SARTRE. Paris: Librairie Philosophique J. Vrin, 2013.

LEOPOLDO e SILVA, Franklin. Ética e Literatura em Sartre - Ensaios Introdutórios. São Paulo: UNESP, 2004.

LEOPOLDO e SILVA, Franklin. Sartre e o humanismo. São Paulo: Editora Barcarolla. 2013.

MOUTINHO, L. D. S. A lógica do engajamento: literatura e metafísica em Sartre. Discurso Departamento de Filosofia da FFLCH DA USP, v. 39, p. 291-320, 2009. 
MULATRIS, Paulin Kilol. Désir, sens, et signification chez Sartre. Paris : L'Harmattan, 1999.

SARTRE, Jean-Paul. A Náusea. Trad. Rita Braga. Editora Nova Fronteira. Rio de Janeiro, 2016.

SARTRE, Jean-Paul. O Existencialismo é um humanismo. In: Coleção: Os Pensadores. Trad. Rita Guedes. São Paulo: Nova Cultural, p. 01-33, 1987

SARTRE, Jean-Paul. O Imaginário - Psicologia fenomenológica da imaginação. Trad. Duda Machado. São Paulo: Editora Ática, 1996.

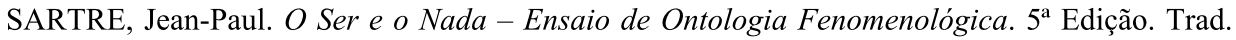
Paulo Perdigão. Petrópolis: Editora Vozes, 1997.

SARTRE, Jean-Paul. Que é a Literatura?. Trad. Carlos Felipe Moisés. São Paulo: Editora Ática, 2004.

SOUZA, Thana Mara. Sartre e a literatura engajada. São Paulo: Edusp. 2008.

SOUZA, Thana Mara. Ética e estética no pensamento de Sartre. Revista Estudos Filosóficos, São Joao del Rei - MG, nº 4, Pág. 84 - 96, 2010.

\section{Notas}

1 Perceber ou imaginar são atos intencionais da consciência, podemos observar isso também na definição de intencionalidade segundo CABESTAN: "Percevoir c'est toujours percevoir quelque chose, imagine, imaginer quelque chose, animer, aimer quelqu'un ou quelque chose, etc. Ainsi, quelle qu'elle soit, la conscience se rapporte toujours à un objet mais chaque fois selon une modalité spécifique qu'il revient à l'analyse intentionnelle de dévoiler." (CABESTAN, 2009, p. 106). A relação entre consciência e mundo em Sartre deriva do princípio da intencionalidade na qual toda consciência é sempre consciência de alguma coisa.

2 A primeira parte da obra $O$ Imaginário de Sartre é denominada de "O certo", pois, de modo semelhante a Descartes que atinge a certeza do Cógito por meio da reflexão, da dúvida metódica, Sartre aqui afirma que num ato de reflexão é possível ter a certeza de que se tem uma imagem por meio dos dados certos que ela entrega, dados que seriam a essência da imagem. "É necessário repetir aqui o que se sabe desde Descartes: uma consciência reflexiva nos entrega dados absolutamente certos; o homem que, num ato de reflexão, toma consciência de "ter uma imagem" não poderia se enganar" (SARTRE, 1996, p. 15).

3 Usar a palavra "mundo" para se referir aos objetos da imaginação é errôneo, pois isso implica a construção de dois mundos, sendo que, em Sartre, não há dois mundos, mas diferentes modalidades de consciência. Assim, nas palavras do próprio Sartre, a utilização de "mundo" é apenas por comodidade. "Quando falamos do mundo dos objetos irreais, estamos empregando por comodidade uma expressão inexata. Um mundo é um todo ligado, no qual cada objeto tem seu lugar determinado e mantém relações com os outros objetos. A própria ideia do mundo implica para seus objetos uma dupla condição: é preciso que estejam rigorosamente individuados; é preciso que estejam em equilíbrio com um meio. É por isso que não há mundo irreal, pois nenhum objeto preenche essa dupla condição" (SARTRE, 1996, p. 175).

4 Segundo CABESTAN, Analogon é: "Termo grego que Sartre usa em O Imaginário para descrever o prolongamento das investigações fenomenológicas de Husserl, a maneira pela qual a consciência imaginante visa seu objeto irreal a partir de uma matéria figurativa." (CABESTAN, 2009, p. 20), (tradução própria). De acordo com BAILLY, o termo grego

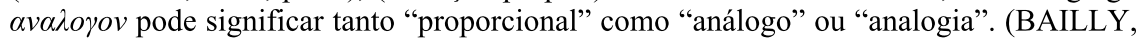
2000 , p. 129) (tradução própria). Neste trabalho optei por não traduzir o conceito analogon, este conceito vai para além de uma simples analogia, ou semelhança. Ele carrega consigo a característica do objeto intencional sendo o intermediário na relação entre real e irreal, possibilitando o contato entre estes dois pontos.

5 Nas palavras de Franklin Leopoldo e Silva: "A situação é o contexto concreto em que os sujeitos exercem a liberdade" (LEOPOLDO E SILVA, 2013, p. 40). "Denominaremos situação a contingencia da liberdade no plenum ser do mundo, na medida em que esse datum que está ai somente para não constranger a liberdade somente se revela a esta 
liberdade enquanto já iluminado pelo fim por ela escolhido. Assim o datum jamais aparece ao Para-si como existente bruto e Em-si; ele se descobre sempre como motivo, já que só se revela à luz de um fim que o ilumina. Situação e motivação se identificam" (SARTRE, 1997, p. 600).

6 Não iremos neste trabalho abordar amplamente o conceito de má-fé, mas cabe uma explicação do que ele seria em relação ao conceito de mentira. A mentira é quando o mentiroso estar a par da verdade que esconde, ele mente para o outro. Já a má-fé tem a mesma estrutura do que a mentira, porém, a consciência afeta a si mesma de má-fé, o sujeito esconde a verdade de si mesmo, não se tem uma dualidade de enganador e enganado. Se na mentira mente-se para outro, mas consciente da verdade, na má-fé, mente-se a si mesmo, colocando a consciência na própria ilusão de verdade. (SARTRE, 1997, p. 93-94). 